\section{Tumor Promoters Stimulate Hyperplasia of Microtubule Organizing Center and Inhibit DNA Synthesis in Cultured Cells}

Renato N. Mascardo and Peter Sherline

Department of Medicine, University of Connecticut

Health Center, Farmington, Connecticut 06032 bstract. Chemical tumor promoters induce significant morphologic changes in several cultured cell models. In this article we describe a new effect of two potent, chemically different tumor promoters, 12-Otetradecanoylphorbol-13-acetate (TPA) and dihydroteleocidin B (DHTB) on cultured human HeLa and melanoma cells. Using immunofluorescence microscopy, we observed that TPA and DHTB induced a dramatic increase in the size ( $\geq 3 \times$ normal diameter) of the centrosome, a microtubule-organizing center, within 24 $h$ of incubation. In HeLa cells the effect was serum- and dose-dependent, was observed in 76-92\% of cells within $72 \mathrm{~h}$ of incubation, and was associated with an increase in cytoplasm-nucleus ratio and proliferation of microtubules from the centrosome. The tumor promoters inhibited serum-induced DNA synthesis in both cell lines. Electron microscopy revealed the presence of clumps of microcentriole bodies or fragments adjacent to the intact centriole.

\section{Introduction}

Chemical tumor promoters are a class of cocarcinogens that are not mutagenic per se but that can induce the formation of tumors when applied repeatedly to the tissue after the initiation of the carcinogenic process (1-3). Although tumor promoters, especially the phorbol diesters (3), were used initially to expound the concept of two-stage carcinogenesis in mouse skin (2), these cocarcinogens were later found to have other significant and interesting biological effects in cultured cells. Tumor promoters induce cytoskeletal changes in chick embryo fibroblasts (4) and mouse macrophages (5), and modulate epidermal

Received for publication 20 December 1983 and in revised form 25 June 1984.

\section{J. Clin. Invest.}

(C) The American Society for Clinical Investigation, Inc.

0021-9738/84/10/1186/07 $\$ 1.00$

Volume 74, October 1984, 1186-1192 growth factor-receptor interaction in breast carcinoma cells (6). In addition to their effects on cell morphology and membrane receptors, phorbol diesters also modulate cell proliferation by either stimulating or inhibiting DNA or cell replication (3). They also modulate cell differentiation inhibiting terminal differentiation in several cell lines including mouse erythroleukemia cells $(3,7)$ and C 1300 neuroblastoma cells (8), and stimulating the differentiation of HL-60 promyelocytic leukemia cells $(9,10)$, a human melanoma cell line (11), and human breast carcinoma cells (9). Thus, tumor promoters could represent analogues of endogenous modulators of cell proliferation, differentiation, transformation, and cytoskeletal function.

In this paper we describe a new action of two potent and chemically different tumor promoters, 12-O-tetradecanoylphorbol-13-acetate (TPA) ${ }^{1}$ and the tumor promoting compound from the mycelia of Streptomyces mediocidicus, dihydroteleocidin B (DHTB) $(10,12)$, on cultured HeLa and melanoma cells. TPA and DHTB induced the formation of large or megacentrosomes in both cell lines; this action on a primary microtubule organizing center $(13,14)$ depended on the presence of serum and was dose and time dependent. Cells with megacentrosomes showed an increased number of microtubules emanating from the centrosome and a reduction in labeling index.

\section{Methods}

Cells. HeLa (American Type Culture Collection CCL 2) and human melanoma SK 90 cells (a gift of Drs. G. Eilon and M. Viola, State University of New York at Stony Brook) were grown on coverslips in Dulbecco's modified Eagle's Medium (DMEM) with 10\% fetal calf serum (FCS) (Gibco Laboratories, Gibco Div., Grand Island, NY), and in a humidified $10 \%$ carbon dioxide atmosphere. Cells in late logarithmic phase of growth were synchronized by total serum deprivation and hydroxyurea $(1 \mathrm{mM})$ for $48 \mathrm{~h}$. TPA, an inactive diester analogue $4 \alpha$-phorbol didecanoate (4 $\alpha \mathrm{PDD}$ ) (Consolidated Midland Corp., Brewster, NY), and DHTB (provided by Drs. T. Sugimura and

1. Abbreviations used in this paper: DHTB, dihydroteleocidin B; DMEM, Dulbecco's modified Eagle's medium; FCS, fetal calf serum; $4 \alpha$ PDD, $4 \alpha$-phorbol didecanoate; TPA, 12-O-tetradecanoylphorbol13-acetate. 
H. Fujiki, National Cancer Center Research Institute, Tokyo) were dissolved in acetone and stored in light-proof test tubes.

Immunofluorescence and autoradiography. Treated cells were fixed in cold methanol and processed for immunofluorescence as previously described $(15,16)$. Centrosomes were localized with a rabbit antiserum (1:50 dilution) specific for high molecular weight microtubule-associated proteins (15) or with an autoantibody (1:100 dilution) in the serum of a scleroderma patient (a gift from Tim Michison, University of California School of Medicine, San Francisco) (17). Simultaneous localization of microtubules and centrosomes was made by incubation of the fixed cells sequentially in buffered saline solution containing a rat monoclonal antibody specific for $\beta$-tubulin (YL1/2, 1:400 dilution, provided by Dr. J. V. Kilmartin, Medical Research Council Laboratory of Molecular Biology, Cambridge, England [18]), the anticentrosome antiserum (rabbit or human), and the appropriate fluorescein- and rhodamine-conjugated goat second antibodies. DNA synthesis was quantitated by the addition of $\left[{ }^{3} \mathrm{H}\right]$ methyl thymidine $(1 \mu \mathrm{Ci} / \mathrm{ml}$; New England Nuclear, Boston, MA) simultaneously with the tumor promoters. After incubation, cells were fixed and processed for immunofluorescence and autoradiography (19). Cells were viewed under a Zeiss Photomicroscope III equipped with epifluorescence optics and a built-in camera (Carl Zeiss Inc., New York). The observer who viewed the cells was unaware of the treatment that the cells received. Photographs were taken with Ektachrome $\mathbf{4 0 0}$ film (Eastman Kodak Co., Rochester, NY).

Electron microscopy. Culture plates were drained of medium and rinsed quickly with $0.2 \mathrm{M}$ cacodylate buffer. The plate was then flooded with $4 \%$ cacodylate buffered glutaraldehyde, allowed to fix for $1 \mathrm{~h}$ at room temperature, and postfixed with $2 \%$ osmium tetroxide (for 30 min). The plate was rinsed with buffer and the surface was scraped with a rubber policeman. Cells were collected in a centrifuge tube (1.5 $\mathrm{ml}$ volume) and spun in a Beckman microfuge B (Beckman Instruments Inc., Fullerton, CA) (for $20 \mathrm{~s}$ ). The resulting pellet was processed by the Electron Microscopy Service (Dr. Concettina Gillies, Department of Pathology). This involved dehydration of the pellet through a graded series of alcohol and propylene oxide followed by embedding in an Epon-Araldite mixture. $1 \mu \mathrm{m}$-thick sections were cut and stained with toluidine for light microscopic viewing and localization of centrosomes. Thin sections containing the centrosomes (60 millimicrons) were stained with uranyl acetate and lead acetate for electron microscopy. Electron micrographs were taken on a Philips EM 300 (Philips Electronic Instruments, Inc., Mahwah, NJ). We analyzed blindly 14 16 electron micrographs of each treatment category for tumor promoter effects.

Quantitation of cytoplasm-nucleus ratio. Quantitation of tumor promoter effect on the cytoplasm-nucleus ratio of HeLa cells was performed as follows: photographic slides containing 7-10 cells were projected onto a screen. The longest and shortest cytoplasmic and nuclear diameters of each cell were measured. The ratio of the mean cytoplasmic diameter and mean nuclear diameter was calculated in 20-25 control and tumor promoter-treated cells.

Chemical reagents. All reagents were from Sigma Chemical Co. (St. Louis, MO) unless otherwise specified.

\section{Results}

Induction of megacentrosome formation. Incubation of HeLa and melanoma cells in DMEM with 10\% FCS and TPA for 24-36 $\mathrm{h}$ induced the formation of large or megacentrosomes (Table I). The megacentrosomes, which were defined as having
Table I. Quantitation of Megacentrosome Effect of Tumor Promoters on HeLa and Melanoma Cells

\begin{tabular}{llc}
\hline & \multicolumn{2}{l}{$\begin{array}{l}\text { Mean \% cells with } \\
\text { megacentrosome } \\
\left(\sum 3 \times \text { diameter of control }\right)\end{array}$} \\
\cline { 2 - 3 } Reagent added to culture medium & HeLa & Melanoma \\
\hline No serum or tumor promoter & 1 & 0.5 \\
FCS (10\%) & 3 & 2 \\
FCS + TPA (100 ng/ml) & 24 & 28 \\
FCS + DHTB $(10 \mathrm{ng} / \mathrm{ml})$ & 34 & 38 \\
FCS + 4 & 4 & 1 \\
TPA & 5 & 2 \\
$4 \alpha$ PDD & 3 & 1 \\
DHTB & 3 & 6
\end{tabular}

Cells rendered quiescent by serum deprivation and hydroxyurea (1 $\mathrm{mM}$ for $48 \mathrm{~h}$ ) were rinsed and incubated in fresh DMEM with 10\% FCS and tumor promoters. After 24 (HeLa) or 36 (Melanoma) $h$ the cells were fixed and processed for immunofluorescence to localize the centrosome. 150-200 cells were counted. Results were expressed as the mean percentage of cells with megacentrosome of two to three experiments. Variability between counts was $\leq 7 \%$.

a diameter at least three times greater than that of control centrosomes, were fluorescently homogeneous or consisted of multiple, closely associated satellite bodies, as seen by staining with either the high molecular weight microtubule-associated protein antiserum or the human autoantibody to centrosomes (Fig. 1). The inactive phorbol diester, $4 \alpha \mathrm{PDD}$, had very little effect on both cell lines. To determine whether this action was unique to the phorbol diester tumor promoters or whether it was more general, we tested the effect of a structurally dissimilar chemical tumor promoter DHTB. DHTB also induced the enlargement of $\mathrm{HeLa}$ and melanoma centrosomes in the presence of $10 \%$ FCS (Table 1).

Dose-response and time course studies. We studied this tumor promoter effect further in HeLa cells. Increasing the concentration of the tumor promoters induced the formation of megacentrosomes in a greater number of cells (Fig. 2). DHTB was the most effective drug, inducing $40 \%$ of cells to form megacentrosomes at a concentration of $1,000 \mathrm{ng} / \mathrm{ml}$ within 24 h. $4 \alpha \mathrm{PDD}$, at a maximal concentration $(1,000 \mathrm{ng} /$ $\mathrm{ml}$ ), induced megacentrosome formation in only $9 \%$ of cells. We observed the effect only in the presence of $10 \%$ FCS (Fig. 2).

To determine if the effect was cumulative, we synchronized the HeLa cells, which exhibit some degree of serum-independent proliferation, at the G1 phase of the cell cycle by total serum deprivation in the presence of $1 \mathrm{mM}$ hydroxyurea for $48 \mathrm{~h}$. Synchronized cells were then incubated in fresh medium (lacking hydroxyurea) containing 10\% FCS and the tumor promoter. We observed that the number of cells showing megacentrosomes increased with longer incubation (Fig. 3). DHTB induced centrosome enlargement in $92 \%$ of cells after 

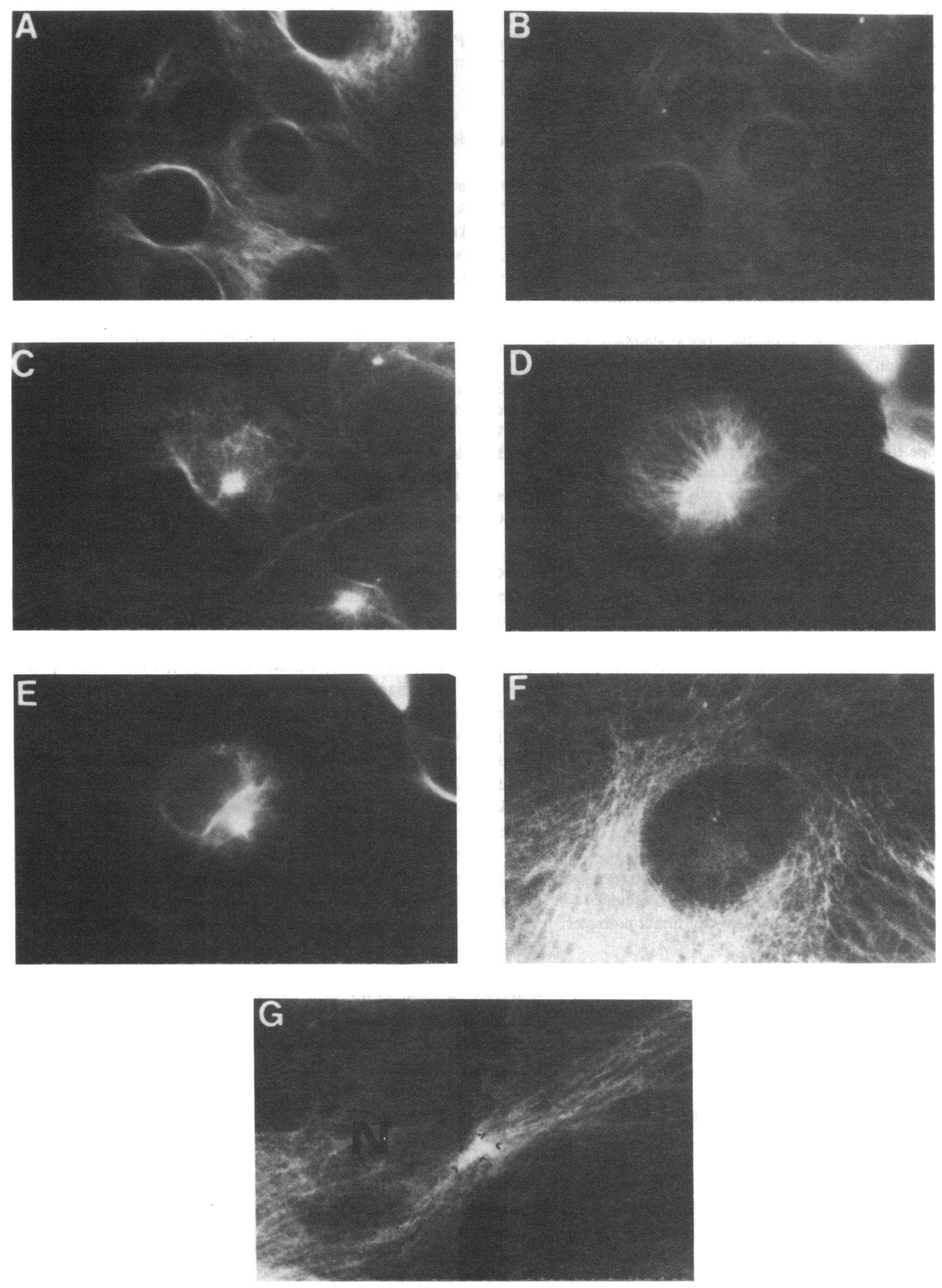

1188 R. N. Mascardo and P. Sherline 


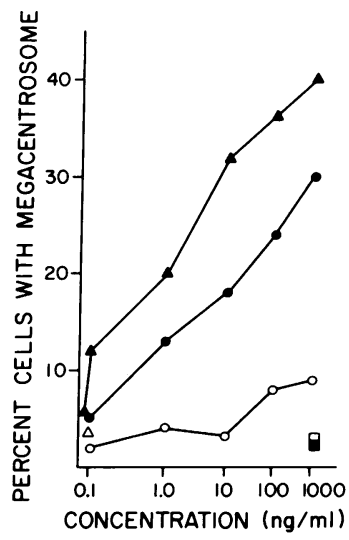

Figure 2. Concentration dependence of megacentrosome effect in HeLa cells. HeLa cells were incubated in DMEM with $10 \%$ FCS plus DHTB $(\triangle)$, TPA (๑), $4 \alpha$ PDD (0), or diluent $(\Delta)$ at varying concentrations, fixed after $24 \mathrm{~h}$, and processed for immunofluorescence. 150-200 cells were counted. Results were expressed as percentage of cells with megacentrosome and represent the mean of two to three experiments. Variability between counts was $57 \%$. . TPA alone; 口, DHTB alone.

$72 \mathrm{~h}$. TPA also produced a similar effect on a smaller proportion (76\%) of cells. The comparatively inactive analogue $4 \alpha \mathrm{PDD}$ induced a relatively small increase in megacentrosome formation (19\%).

Induction of other morphologic changes. HeLa cells exposed to tumor promoters exhibited morphologic changes, including an increase in cytoplasm-nucleus ratio (Table II) and a more flattened, fibroblastoid shape (Fig. $1, C$ and $D$ ). Since the centrosome is a major cytoplasmic microtubule-organizing center $(13,14)$, the induction of centrosomal hyperplasia could

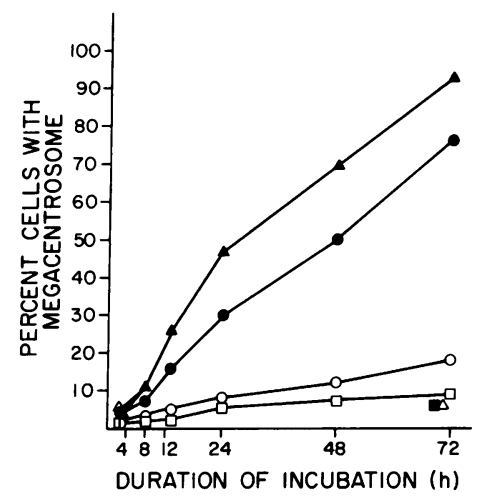

Figure 3. Time course of megacentrosome effect of tumor promoters in HeLa cells. Synchronized HeLa cells were rinsed and incubated in fresh DMEM with $10 \%$ FCS plus DHTB (10 $\mathrm{ng} / \mathrm{ml})$, TPA $(100 \mathrm{ng} / \mathrm{ml})$ $4 \alpha \operatorname{PDD}(1,000 \mathrm{ng} / \mathrm{ml})$, or diluent. Cells were fixed after varying incubation periods and processed for immunofluorescence. 150-200 cells were counted. Results were expressed as mean percentage of cells with megacentrosome of two to three experiments. Variability between counts was $59 \%$. $\triangle$, DHTB + FCS; •, TPA + FCS; 0, $4 \alpha$ PDD + FCS; $\square$, acetone + FCS; -, DHTB alone; $\triangle$, TPA alone.
Table II. Effect of Tumor Promoters on Cytoplasm-Nucleus Ratio of HeLa Cells

\begin{tabular}{ll}
\hline Reagent added to culture medium & $\begin{array}{l}\text { Cytoplasm-nucleus ratio } \\
(\text { mean } \pm S E)\end{array}$ \\
\hline 1. No serum or tumor promoter & $1.7 \pm 0.07$ \\
2. FCS $(10 \%)$ & $2.0 \pm 0.12$ \\
3. TPA $(100 \mathrm{ng} / \mathrm{ml})$ & $1.8 \pm 0.08$ \\
4. $4 \alpha$ PDD $(100 \mathrm{ng} / \mathrm{ml})$ & $1.8 \pm 0.10$ \\
5. DHTB $(10 \mathrm{ng} / \mathrm{ml})$ & $1.9 \pm 0.09$ \\
6. TPA + FCS & $2.5 \pm 0.11^{*}$ \\
7. $4 \alpha$ PDD + FCS & $2.1 \pm 0.14$ \\
8. DHTB + FCS & $2.8 \pm 0.12^{*}$
\end{tabular}

Quiescent cells were incubated in fresh DMEM, 10\% FCS, and tumor promoters. After $24 \mathrm{~h}$, the cells were fixed and processed for double immunofluorescence to localize the microtubules and centrosome. Microphotographs of groups of cells (7-10 cells/slide) were analyzed for tumor promoter effect on cytoplasm-nucleus ratio (see Methods). Results were expressed as the mean ratio \pm SE of 25-30 cells per experimental category.

$* P<0.01$ compared with categories $1-5$ and 7 .

affect its microtubule-initiating function. By simultaneously staining the same cell with antibodies to tubulin and the centrosome, we observed, in cells treated with either TPA or DHTB plus serum, an extensive cytoplasmic microtubule network in which most microtubules emanated from the megacentrosomes (Fig. 1 D). This was in marked contrast to control cells that exhibited less numerous cytoplasmic microtubules, the bulk of which did not appear to originate from the centrosome (Fig. 1, $A$ and $B$ ).

Inhibitory effect on DNA synthesis. In monitoring the cumulative effect of the tumor promoters on centrosomal enlargement, we observed an apparent decrease in cell number in cultures exposed to either TPA or DHTB and FCS. To determine whether these tumor promoters were antiproliferative in HeLa and melanoma cells and to determine the relationship of the centrosomal enlargement to DNA synthesis, we measured the cumulative nuclear labeling index of synchronized cells after exposure to $10 \%$ FCS and TPA for 24-36 h. Seruminduced DNA synthesis was partially inhibited in cells exposed to TPA and DHTB (Table III).
Figure 1. Immunofluorescence localization of hyperplastic microtubule-organizing centers. To quiescent $\mathrm{HeLa}$ and melanoma cells were added DMEM with $10 \%$ FCS plus TPA $(100 \mathrm{ng} / \mathrm{ml}), 4 \alpha$ PDD (100 $\mathrm{ng} / \mathrm{ml})$, or DHTB $(10 \mathrm{ng} / \mathrm{ml})$. Cells were fixed $48 \mathrm{~h}$ later and processed for immunofluorescence to localize the centrosome and microtubules. Control HeLa cells treated with $4 \alpha$ PDD exhibited microtubules $(A)$ and centrosomes $(B)$ with very few or no tubules emanating from them. FCA + TPA-treated HeLa cells $(C)$ demonstrated megacentrosomes (central cell and at 4 o'clock) and a normal centrosome (2 o'clock). A cell incubated in FCS + DHTB exhibited a megacen- trosome $(E)$ and many fibers emanating from it $(D)$. FCS + TPAtreated melanoma cell $(G)$ exhibited a large centrosome consisting of multiple bodies (arrowheads). Melanoma cell treated with FCS $+4 \alpha$ PDD had a pair of closely spaced centrosomes of normal size $(F)$. The centrosome was localized with either an antibody to high molecular weight microtubule-associated proteins $(B$ and $C$ ) or an autoantibody in a scleroderma serum $(E-G)$. N, nucleus. Magnifications: $(A$ and $B) 1,125 ;(C) 1,800 ;(D$ and $E) 1,440$; and $(F$, and $G)$ 1,800 . 

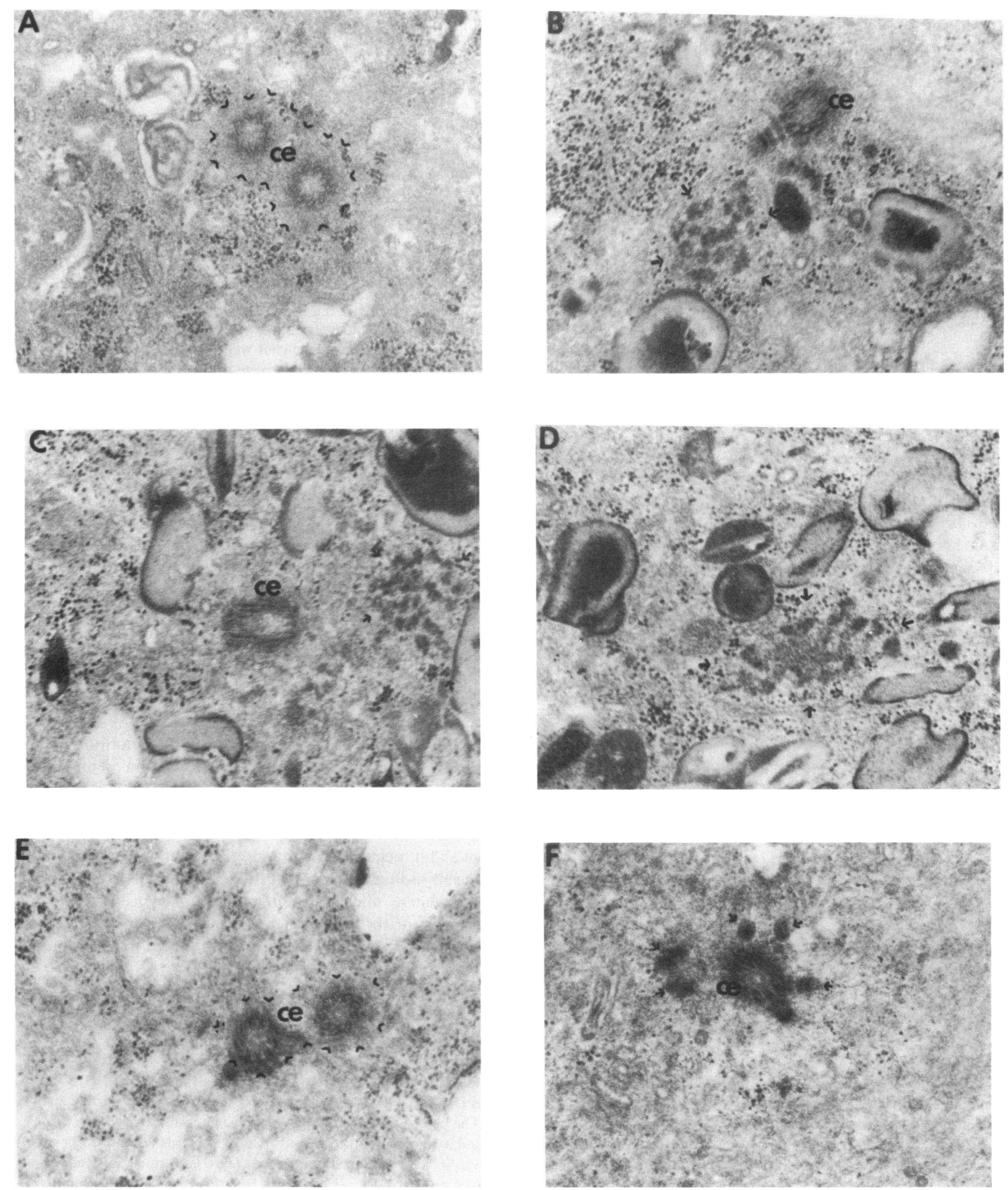
Table III. Effect of Tumor Promoters on DNA Synthesis of HeLa and Melanoma Cells

\begin{tabular}{|c|c|c|c|c|}
\hline \multirow{3}{*}{$\begin{array}{l}\text { Reagent added to } \\
\text { culture medium }\end{array}$} & \multicolumn{4}{|c|}{ Labeling index (mean $\pm S E$ ) } \\
\hline & \multicolumn{2}{|l|}{ HeLa } & \multicolumn{2}{|c|}{ Melanoma } \\
\hline & $24 \mathrm{~h}$ & $36 \mathrm{~h}$ & $24 \mathrm{~h}$ & $36 \mathrm{~h}$ \\
\hline \multicolumn{5}{|c|}{ No serum or tumor } \\
\hline promoter & $50 \pm 2.4$ & $77 \pm 1.2$ & $14 \pm 1.4$ & $10 \pm 1.2$ \\
\hline FCS (10\%) & $94 \pm 1.7$ & $94 \pm 1.2$ & $49 \pm 2.0$ & $64 \pm 2.2$ \\
\hline \multicolumn{5}{|l|}{ FCS + TPA } \\
\hline$(100 \mathrm{ng} / \mathrm{ml})$ & $61 \pm 3.1$ & $80 \pm 2.5$ & $26 \pm 1.2$ & $24 \pm 1.7$ \\
\hline \multicolumn{5}{|l|}{ FCS + DHTB } \\
\hline$(10 \mathrm{ng} / \mathrm{ml})$ & $55 \pm 2.2$ & $70 \pm 1.6$ & $18 \pm 1.4$ & $16 \pm 2.0$ \\
\hline \multicolumn{5}{|l|}{$\mathrm{FCS}+4 \alpha \mathrm{PDD}$} \\
\hline$(100 \mathrm{ng} / \mathrm{ml})$ & $92 \pm 1.7$ & $92 \pm 2.2$ & $44 \pm 2.1$ & $68 \pm 1.6$ \\
\hline TPA & $50 \pm 1.7$ & $69 \pm 2.2$ & $18 \pm 0.8$ & $14 \pm 1.2$ \\
\hline DHTB & $52 \pm 1.9$ & $69 \pm 1.8$ & $16 \pm 1.4$ & $16 \pm 2.0$ \\
\hline $4 \alpha \mathrm{PDD}$ & $53 \pm 2.0$ & $71 \pm 2.0$ & $18 \pm 0.8$ & $21 \pm 1.7$ \\
\hline
\end{tabular}

Quiescent cells were incubated in fresh DMEM with 10\% FCS plus TPA (100 $\mathrm{ng} / \mathrm{ml})$, DHTB $(10 \mathrm{ng} / \mathrm{ml})$, or $4 \alpha \mathrm{PDD}(100 \mathrm{ng} / \mathrm{ml})$, and tritiated thymidine (1 $\mu \mathrm{Ci} / \mathrm{ml})$, at time 0 and fixed $24-36 \mathrm{~h}$ later. After fixation, the cells were processed for immunofluorescence and autoradiography. Cumulative DNA synthesis was expressed as the mean percentage of 200 cells with labeled nucleus \pm SE of two experiments.

Electron microscopy. To determine more definitively which component of the centrosome was affected by the tumor promoters, we processed the cells exposed to TPA or $4 \alpha$ PDD and $10 \%$ FCS (for $48 \mathrm{~h}$ ) for electron microscopy. In 16 sections of control (4 $\alpha$ PDD + FCS) HeLa cells, the centrosome consisted of a pair of centrioles and an organelle-free pericentriolar zone (arrowheads, Fig. $4 \mathrm{~A}$ ). TPA induced an apparent increase in the size of the centrosome in 14 sections studied (Fig. 4, B$D$ ). This increase in size was due in part to the presence of clumps of centriole fragments (Fig. 4, $B-D$, arrows) located near the intact centriole (Fig. 4, $B$ and $C$ ).

In melanoma cells, TPA induced the formation of centriole fragments adjacent to the intact centriole (Fig. $4 F$, arrows). Control cells did not show this phenomenon (Fig. $4 E$ ). Very few microtubules were preserved in HeLa and melanoma cells processed for electron microscopy.

\section{Discussion}

TPA induces rapid (1-2 h) and slow ( $>6 \mathrm{~h}$ ) cytoskeletal changes in a number of cell lines. The slow alterations in cell mor- phology include an increase in the cytoplasm-nucleus ratio and flattening of MCF-7 cells (6), and the formation of dendrite-like structures in human melanoma cells (11). These morphologic changes are associated with a decline in DNA and cell replication in both cell lines, and stimulation of protein (MCF-7) and melanin (melanoma cells) synthesis. Phaire-Washington et al. (5) observed that TPA enhanced the radial arrangement and number of microtubules emanating from the centrosphere to the peripheral cytoplasm of mouse macrophages within 90 min of incubation. These early changes were associated with an increase in pinocytic rate $72 \mathrm{~h}$ later (5). It appears that tumor promoters can induce a major reorganization of cytoskeletal components, including the microtubules, that is associated with fundamental changes in cell function. In the present study, the tumor promoters induced a dramatic reorganization of microtubules in $\mathrm{HeLa}$ and melanoma cells as shown by immunofluorescence microscopy. This was characterized by the hyperplasia of the centrosomal microtubule organizing center from which a great number of microtubules emanated.

Although the electron microscopic study demonstrated that the immunofluorescence finding of centrosomal enlargement was associated with the presence of clumps of microcentriole bodies, the exact nature and function of these bodies are unclear. Whether tumor promoters in the presence of serum induce multiple replications of one of the centriole pair and whether microtubules nucleate directly from the centrosomal clump or from the amorphous region surrounding the clump remain to be determined.

Although the mechanism of centrosomal enlargement induced by tumor promoters is unclear, it appears to depend upon one of several serum components. Recently, Yamanishi et al. have suggested that the biochemical target of TPA in platelets is located on the membrane and that the protein kinase C-phospholipid complex is a TPA receptor itself $(20$, 21). They found that optimal serotonin release by platelets occurred only when protein kinase $C$ activation by TPA was coupled with calcium mobilization by the calcium ionophore, A23187. Thus, TPA or DHTB could be acting in conjunction with a humoral factor found in serum that induces calcium entry into the cytoplasm. Finally, it is interesting that this common centrosomal effect of two chemically different tumor promoters is associated with certain morphological (increased cytoplasm-nucleus ratio in HeLa cells) and biochemical (decreased DNA synthesis) events observed in cell differentiation.
Figure 4. Electron microscopy of HeLa and melanoma centrosomes Synchronized HeLa and melanoma cells were incubated in DMEM, $10 \% \mathrm{FCS}$, and the tumor promoter for $\mathbf{4 8} \mathrm{h}$ and processed for electron microscopy (see Methods). (A) The centrosome of a control (FCS $+4 \alpha \mathrm{PDD}$ ) HeLa cell demonstrated a pair of centrioles (ce) bounded by an amorphous, pericentriolar cloud (arrowheads). (B) TPA $(100 \mathrm{ng} / \mathrm{ml})+$ FCS induced the formation of a clump of discrete electron-dense bodies (arrows) near the intact centriole (ce).
(C) A similar phenomenon was seen in a HeLa cell treated with DHTB $(10 \mathrm{ng} / \mathrm{ml})+$ FCS. $(D)$ The clump of microcentriole bodies consisted of 15-20 discrete fragments (arrows). (E) A control melanoma cell exhibited a centrosome consisting of a pair of centrioles (ce) surrounded by a pericentriolar cloud (arrowheads). $(F)$ TPA induced the formation of electron-dense bodies (arrows), which were localized near the intact centriole (ce). ( $A-F)$ Magnification, 50,000. 
It is possible that the microtubule organizing center hyperplasia and centriolar fragmentation induced by tumor promoters are actually morphologic markers of a cell's transition into a more differentiated or nonproliferative state. However, the mechanistic relationship, if any, between the centrosomal changes and decreased DNA synthesis remains to be elucidated.

\section{Acknowledgments}

This work was supported in part by the Juvenile Diabetes Foundation, the University of Connecticut Research Foundation (Dr. Mascardo), National Institutes of Health grant GM 22497, and a Research Career Development Award (Dr. Sherline).

\section{References}

1. Boutwell, R. K. 1974. The function and mechanism of promoters of carcinogenesis. Crit. Rev. Toxicol. 2:419-443.

2. Van Duuren, B. L. 1969. Tumor promoting agents in two-stage carcinogenesis. Prog. Exp. Tumor Res. 11:31-68.

3. Diamond, L., T. G. O'Brien, and W. M. Baird. 1980. Tumor promoters and the mechanism of tumor promoters. Adv. Cancer Res. 32:1-74.

4. Rifkin, D. B., R. M. Crowe, and R. Pollack. 1979. Tumor promoters induce changes in the chick embryo fibroblast cytoskeleton. Cell. 18:361-368.

5. Phaire-Washington, L., S. C. Silverstein, and E. Wang. 1980. Phorbol myristate acetate stimulates microtubule and $10-\mathrm{nm}$ filament extension and lysosome redistribution in mouse macrophages. $\mathrm{J}$. Cell Biol. 86:641-655.

6. Osborn, C. K., B. Hamilton, M. Nover, and J. Ziegler. 1981. Antagonism between epidermal growth factor and phorbol ester tumor promoters in human breast cancer cells. J. Clin. Invest. 67:943-951.

7. Fibach, E., R. Ganbarie, P. A. Shaw, G. Maniatis, R. C. Reuben, S. Sassa, R. A. Rifkind, and P. A. Marks. 1979. Tumor promotermediated inhibition of cell differentiation: suppression of the expression of erythroid functions in murine erythroleukemia cells. Proc. Natl. Acad. Sci. USA 76:1906-1910.

8. Ishii, D. N., E. Fibach, H. Yamasaki, and I. B. Weinstein. 1978. Tumor promoters inhibit morphological differentiation in cultured mouse neuroblastoma cells. Science (Wash. DC). 200:556-559.

9. Huberman, E., and M. F. Callahan. 1979. Induction of terminal differentiation in human promyelocytic leukemia cells by tumorpromoting agents. Proc. Natl. Acad. Sci. USA 76:1293-1297.

10. Sugimura, T., H. Fujiki, M. Mori, M. Nakayasu, M. Terada, K. Umezawa, and R. E. Moore. 1982. Teleocidin: new naturally occurring tumor promoter. In Cocarcinogenesis and Biological Effects of Tumor Promoters. E. Hecker, N. E. Fusenig, W. Kung, F. Marks, and H. W. Thielam, editors. Raven Press, New York, 69-73.

11. Huberman, E., C. Heckman, and R. Langenbach. 1979. Stimulation of differentiated functions in human cells by tumor promoting agents and dimethyl sulfoxide. Cancer Res. 39:2618-2624.

12. Hirakawa, T., H. Fujiki, and T. Sugimura. 1982. A new tumorpromoting agent, dihydroteleocidin B, markedly enhances chemically induced malignant cell transformation. Science (Wash. DC). 216:527529.

13. Weber, K., and M. Osborne. 1981. Microtubule and intermediate filament networks in cells viewed by immunofluorescence microscopy. In Cytoskeletal Elements and Plasma Membrane Organization. Elsevier/ North Holland, New York. 1-53.

14. Brinkley, B. R., S. H. Fistel, J. M. Marcum, and R. L. Pardur. 1980. Microtubules in cultured cells: indirect immunofluorescent staining with tubulin antibody. Int. Rev. Cytol. 63:59-95.

15. Mascardo, R. N., P. Sherline, and J. Weatherbee. 1982. Localization of high molecular weight microtubule-associated protein $\left(\mathrm{MAP}_{1}\right.$ and $\mathrm{MAP}_{2}$ ) in HeLa microtubule-organizing center. Cytobios. 35:113-127.

16. Sherline, P., and R. Mascardo. 1982. Epidermal growth factorinduced centrosomal separation: mechanism and relationship to mitogenesis. J. Cell Biol. 95:316-332.

17. Calarco-Gillam, P. O., M. C. Siebert, R. Hubble, T. Michison, and M. Kirschner. 1983. Centrosome development in early mouse embryos as defined by an auto-antibody against pericentriolar material. Cell. 35:621-629.

18. Kilmartin, J. V., B. Wright, and C. Milstein. 1982. Rat monoclonal antitubulin antibodies derived by using new nonsecreting rat cell line. J. Cell Biol. 93:576-582.

19. Baserga, R., and D. Malamud. 1969. Autoradiography. Hoeber New York. 17.

20. Yamanishi, J., Y. Takai, K. Kaibuchi, K. Sano, M. Castagna, and Y. Nishizuka. 1983. Synergistic functions of phorbol ester and calcium in serotonin release from human platelets. Biochem. Biophys. Res. Commun. 112:778-786.

21. Castagna, M., Y. Takai, K. Kaibuchi, K. Sano, U. Kikkawa, and Y. Nishizuka. 1982. Direct activation of calmodulin-activated phospholipid-dependent protein kinase by tumor promoting phorbol esters. J. Biol. Chem. 257:7847-7851. 